\title{
Does Simple Face Mask or Diffuser Mask Matter in the First Hour Treatment of Carbon Monoxide Intoxication? A Prospective Randomized Clinical Study
}

\author{
Abdullah Cuneyt Hocagil ${ }^{1}$ (D), Hilal Hocagil ${ }^{1}$ (D), Mehmet Tatli ${ }^{2}$ (iD \\ 'Department of Emergency Medicine, Bulent Ecevit University School of Medicine, Zonguldak, Turkey \\ ${ }^{2}$ Department of Emergency Medicine, Health Sciences University Kayseri Training and Research Hospital, Kayseri, Turkey
}

Cite this article as: Hocagil AC, Hocagil H, Tatli M. Does Simple Face Mask or Diffuser Mask Matter in the First Hour Treatment of Carbon Monoxide Intoxication? A Prospective Randomized Clinical Study. Eurasian J Emerg Med. 2018 ; 17 (4): 165-70.

\begin{abstract} levels after the first hour of $\mathrm{O}_{2}$ treatment in patients with $\mathrm{CO}$ intoxication.

\section{Introduction}

Carbon monoxide (CO) intoxication is the most common cause of death among all intoxications (1-3). It affects many organs through tissue hypoxia and causes damage at the cellular level. The central nervous system and the heart are the most important organs affected (4). CO can cause permanent neurological sequel (5), changes in heart rate, arrhythmia, myocardial damage, necrosis, cardiogenic shock, and sudden cardiac death.
\end{abstract}

Aim: In patients who do not have any indication for hyperbaric oxygen $\left(\mathrm{O}_{2}\right)$ treatment, the main treatment to eliminate carbon monoxide (CO) is by giving $\mathrm{O}_{2}$ using a face mask. In the absence of a non-rebreathing face mask, a diffuser mask (DMG) or simple face mask (SMG) is an option that can be used for treatment. There are insufficient data about the acute efficacy of these masks. To study the ability of DMG and SMG in lowering carboxyhemoglobin (COHb)

Materials and Methods: This was a prospective randomized clinical study conducted in patients aged $\geq 16$ years old who were diagnosed with CO intoxication. They were randomly given $15 \mathrm{~L} / \mathrm{min} \mathrm{O}_{2}$ (from hospital central $\mathrm{O}_{2}$ supplies) treatment with DMG $(n=29)$ or SMG $(n=52)$. Partial pressure of $\mathrm{O}_{2}\left(\mathrm{PaO} \mathrm{O}_{2}\right.$ ), carbon dioxide, and $\mathrm{COHb}$ levels and saturation of $\mathrm{O}_{2}$ were measured before and after $1 \mathrm{~h}$ of treatment.

Results: A total of 81 (42 female and 39 male) patients with a mean age of 39.1 \pm 14.7 years were included in the study. There were no differences with regard to age, gender, body mass index, comorbidity, source of $\mathrm{CO}$, initial symptoms, and initial $\mathrm{COHb}$ levels before treatment. After the first hour of treatment, DMG had lower mean $\mathrm{COHb}(\mathrm{mg} / \mathrm{dL})$ levels $(9.6 \pm 5.0$ vs. $12.8 \pm 6.2, \mathrm{p}=0.0203)$ and higher mean $\mathrm{PaO}_{2}$ levels $(224.4 \pm 56.5 \mathrm{vs}$. 183.4 $\pm 63.7, \mathrm{p}=0.0046)$ than $\mathrm{SMG}$.

Conclusion: Diffuser mask (DMG) appears to be better than simple face mask (SMG) in the first hour of treatment of CO intoxication.

Keywords: Carbon monoxide intoxication, diffuser mask, simple face mask, emergency department

It is important to start treatment early in cases of CO intoxication, as exposure time is one of the key factors that determine the severity of toxicity (6). Treatment consists of hemodynamic stabilization and elimination of $\mathrm{CO}$. The elimination largely includes administering $100 \%$ oxygen $\left(\mathrm{O}_{2}\right)$ with non-rebreathing face mask or providing hyperbaric $\mathrm{O}_{2}$ therapy (HBOT) (7-9). In the absence of a nonrebreathing face mask, diffuser mask (DMG) and simple face mask (SMG) are two types of masks commonly used. To the best of our

ORCID IDs of the authors: A.C.H. 0000-0002-1675-9754; H.H. 0000-0001-7314-752X; M.T. 0000-0001-5907-9161.

This study was presented in Intercontinental Emergency Medicine Congress as a poster on May 2014, Antalya, Turkey.

Correspondence to: Hilal Hocagil e-mail: drhocagil@gmail.com

Received: 29.06.2017 • Accepted: 13.09.2017

(C) Copyright 2018 by Emergency Physicians Association of Turkey - Available online at www.eajem.com

DOI: 10.5152/eajem.2018.46320 
knowledge, there is no study that compares the effectiveness of DMG with an SMG on CO intoxication treatment.

The aim of the present study was to evaluate the effectiveness of DMG and SMG on decreasing the levels of carboxyhemoglobin $(\mathrm{COHb})$ after the first hour of $\mathrm{CO}$ intoxication treatment.

\section{Materials and Methods}

\section{Study design}

This was a prospective randomized clinical study conducted between December 1, 2012 and April 30, 2013. Patients were recruited from the emergency department (ED) of Dr. Lutfi Kırdar Kartal Training and Research Hospital, which has an average daily admittance of 800-1000 patients. Ethics committee approval was received for this study from the Ethics Committee of Dr. Lutfi Kirdar Kartal Training and Research Hospital (Approval Date: 30.04.2012, No:8951337/1009/141). Written informed consent was obtained from all patients who participated in this study.

\section{Study population}

Patients who were $>16$ years old, diagnosed with $\mathrm{CO}$ intoxication $(\mathrm{COHb}>10 \mathrm{mg} / \mathrm{dL})$, having no indication of hyperbaric $(\mathrm{n}=48)$, or having indications of hyperbaric but needed to be monitored in the emergency room until transferred to another facility with available HBOT after at least $1 \mathrm{~h}$ of $\mathrm{O}_{2}$ treatment with one of the masks used $(n=33)$ were included in the study. Patients having no need for intensive care, receiving proper treatment protocol, and having full medical records were also included.

Patients who were $<16$ years old, refused to participate, and who needed intubation were excluded from the study. Patients with diseases that cause hemoglobin dissociation curve shift to the left or diseases that cause increased endogenous $\mathrm{CO}$ production, such as chronic obstructive pulmonary disease (COPD), asthma, sickle cell anemia, polycythemia vera, and smoking, were also excluded.

Patients who met the enrollment criteria were randomized to cohorts according to randomization numbers assigned by the computer and randomized (2:1 within each group) to receive $\mathrm{O}_{2}$ with DMG or SMG (we had limited numbers of DMG in ED compared with SMG).

\section{Data collection and processing}

Patients were divided into two groups: one group treated with SMG and the other group treated with DMG. Five minutes after diagnosis, both groups received $15 \mathrm{~L} \mathrm{O}_{2}$ therapy/min from hospital central $\mathrm{O}_{2}$ supplies.

Data on existing symptoms, height and weight of the patients, causes of $\mathrm{CO}$ exposure, smoking habits, and comorbidities were collected. Patients' brachial arterial blood gases, $\mathrm{COHb}$, partial pressure of $\mathrm{O}_{2}$ $\left(\mathrm{PaO}_{2}\right)$, saturation of $\mathrm{O}_{2}\left(\mathrm{SaO}_{2}\right), \mathrm{COHb}$ values on admission, and $\mathrm{PaO}_{2}$ and $\mathrm{SaO}_{2}$ values $1 \mathrm{~h}$ after treatment were recorded for each patient. Before receiving treatment, electrocardiography (ECG) was obtained, and respiratory rate was noted for each patient. ECG was repeated 1 $\mathrm{h}$ after treatment, and speed was evaluated in terms of rhythm and ECG disparities.
All blood gas determinations were made by the Radiometer ABL 700 (441R0226N010) (Radiometer Medical, Bronshoj, Denmark). The ABL 700 series blood gas analyzer that incorporates co-oximetry, electrolyte, and metabolite measurements uses heparinized whole blood as the preferred sample (10). A $195 \mu \mathrm{L}$ blood sample was required by the $A B L 700$. This analyzer is designed for laboratory use only and is not portable. The ABL 700 was routinely calibrated every 4 $\mathrm{h}$ according to the manufacturer's recommendations (11).

\section{Features of the masks used}

Diffuser mask (OxyMask; Southmedic Inc., Ontario, Canada) is an open-system mask that can deliver $24 \%-90 \%$ fractional inspired $\mathrm{O}_{2}$ concentration when $\mathrm{O}_{2}$ flow is between 1 and $15 \mathrm{~L} / \mathrm{min}$. The mask consists of two parts: a diffuser system that forms a vortex with $\mathrm{O}_{2}$ molecules and a pin. An umbrella-shaped pin is located in the triangle-shaped diffuser cup. This form of pin channels provides a vortex of the gas stream. High velocity accelerates this vortex. This vortex, which formed through angled diffuser cup portion, is routed directly to the mouth and nose (12) (Figure 1).

Simple face mask (HS-3031; Hsiner, Taichung Hsien, Taiwan), placed on the patient's nose and mouth, is made of transparent plastic reservoirs. It is fixed to the patient's head with an elastic strip. $\mathrm{O}_{2}$ reaches the mask with a small connection tube. There are holes on both sides of the mask, and these holes deplete the exhaled air. These holes also allow mixing of room air into the reservoir (Figure 2).

\section{Statistical analysis}

The patient characteristics between the two groups were compared using the chi-square test or Fisher's exact test for categorical variables and the Student's t-test for continuous variables. Differences between the two groups in terms of before and after treatment values of $\mathrm{COHb}, \mathrm{PaO}_{2}$, and $\mathrm{SaO}_{2}$ were compared using the WilcoxonMann-Whitney test, as the parametric test assumptions did not meet. Statistical analyses were performed using the Statistical Package for Social Sciences 12.0 software (SPSS Inc.; Chicago, IL, USA). A twosided $p<0.05$ was considered statistically significant.

\section{Results}

Between the dates of our study, 151 patients were diagnosed with $\mathrm{CO}$ intoxication in the ED. Among those, 20 patients were excluded due to missing information on their medical records or standard treatment disruptions. The other 23 patients were excluded from the study, as they received HBOT $(n=18)$ within the first hour of treatment and had admission to the intensive care unit $(n=5)$ in the first hour they were admitted to the ED. Twenty-seven patients were also excluded from the study, as 2 of them had asthma, 4 had COPD, and 21 were smokers (Figure 3).

A total of 81 patients were enrolled in the study. There were 42 female and 39 male patients. The mean age of the patients was $39.11 \pm 14.7$ years. DMG was used for $35.8 \%$ of the patients. Among all patients, the two most common complaints were headache (50.6\%) and dizziness (14.8\%), respectively. Other complaints were fatigue, confusion, syncope, nausea, vomiting, and shortness of breath. The least common complaint was chest pain (1.3\%) (Table 1). There were no significant differences in patient's age, sex, and body mass index 


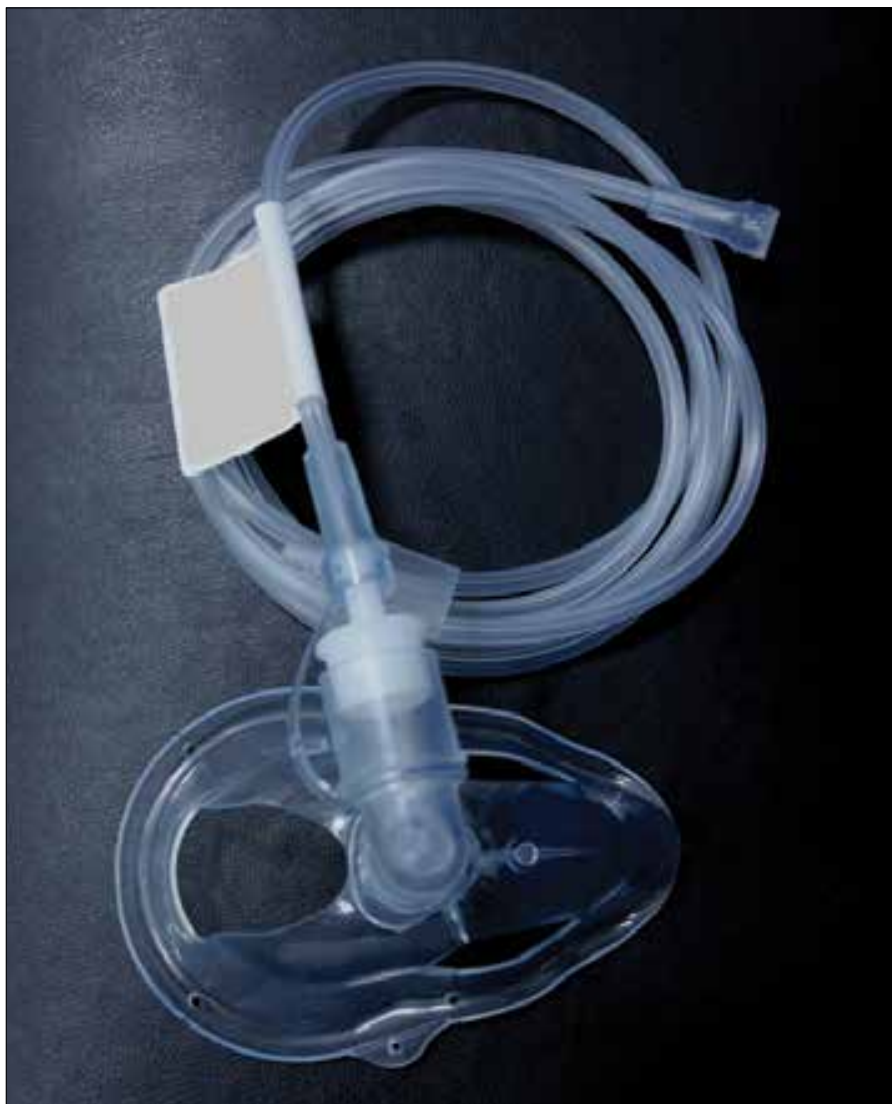

Figure 1. Diffuser mask
(BMI) between patients who were treated with SMG and patients who were treated with DMG (Table 1).

Of the study participants, 75 were exposed to $\mathrm{CO}$ due to stove smoke, whereas 6 were exposed to $\mathrm{CO}$ due to house fire. There were no statistically significant differences between patients before treatment with SMG and patients treated with DMG in terms of the mean values of the initial $\mathrm{COHb}, \mathrm{PaO}_{2}$, and $\mathrm{SaO}_{2}$ (Table 1).

The mean value of $\mathrm{PaO}_{2}(183.4 \pm 63.7 \mathrm{~mm} \mathrm{Hg})$ in patients after treatment with SMG was higher than that $(224.4 \pm 56.5 \mathrm{~mm} \mathrm{Hg})$ in patients treated with DMG $(Z=2.83, p=0.0046)$ (Table 1). The

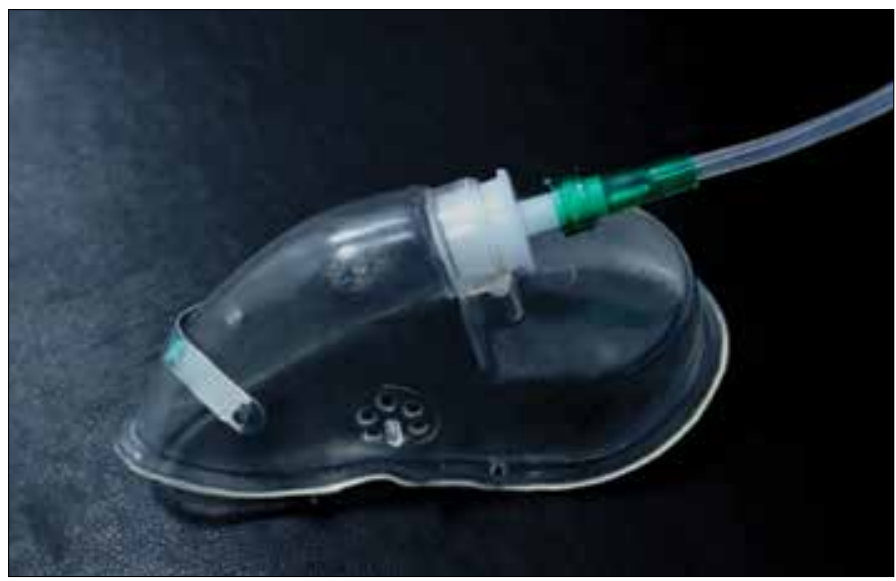

Figure 2. Simple face mask

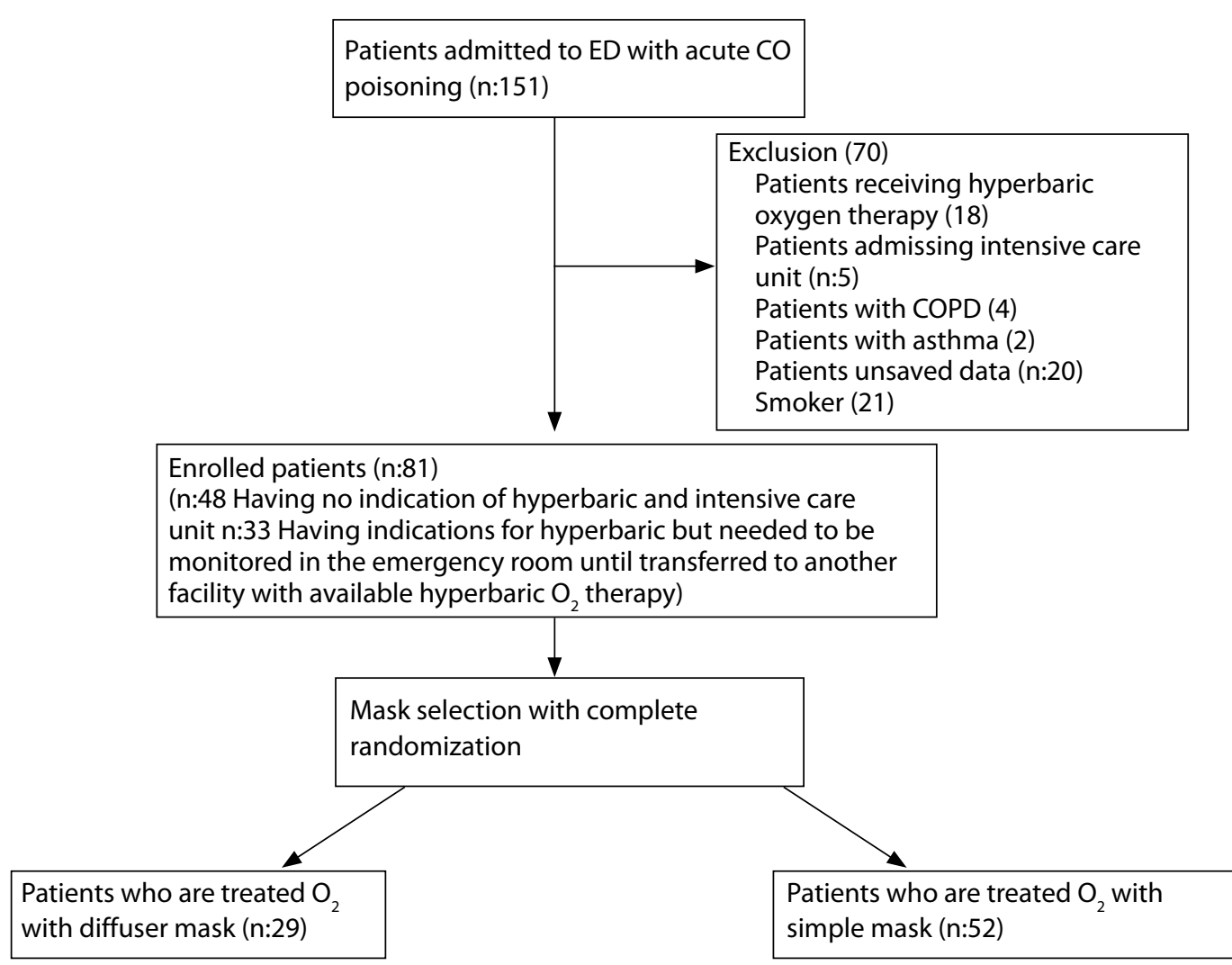

Figure 3. Flowchart of the study 
Table 1. Demographic, clinical, and laboratory characteristics of the two groups

\begin{tabular}{|c|c|c|c|c|}
\hline & Diffuser mask n (\%) & Simple face mask $\mathbf{n}(\%)$ & $\mathbf{p}$ & Total n (\%) \\
\hline n (\%) & $29(35.8)$ & $52(64.2)$ & - & $81(100.0)$ \\
\hline \multicolumn{5}{|l|}{ Gender } \\
\hline Female & $18(62.1)$ & $24(46.2)$ & \multirow{2}{*}{$0.1693^{\ddagger}$} & $42(51.9)$ \\
\hline Male & $11(37.9)$ & $28(53.8)$ & & $39(48.1)$ \\
\hline \multicolumn{5}{|l|}{ Symptoms } \\
\hline Headache & $16(19.75)$ & $25(30.85)$ & \multirow{8}{*}{$0.690^{*}$} & $41(50.6)$ \\
\hline Vertigo & $7(8.64)$ & $5(6.16)$ & & $12(14.8)$ \\
\hline Weakness & $2(2.47)$ & $1(1.23)$ & & $3(3.7)$ \\
\hline Confusion & 0 & $4(4.9)$ & & $4(4.9)$ \\
\hline Syncope & $3(3.74)$ & $6(7.46)$ & & $9(11.2)$ \\
\hline Nausea/vomiting & $1(1.2)$ & $6(7.4)$ & & $7(8.6)$ \\
\hline Chest pain & 0 & $1(1.3)$ & & $1(1.3)$ \\
\hline Dyspnea & 0 & $4(4.9)$ & & $4(4.9)$ \\
\hline \multicolumn{5}{|l|}{ Source of CO } \\
\hline Stove fumes & $28(34.39)$ & $47(58.02)$ & \multirow{2}{*}{$0.412^{*}$} & 75 (92.59) \\
\hline \multirow[t]{2}{*}{ House fire } & $1(1.23)$ & $5(6.18)$ & & $6(7.41)$ \\
\hline & Diffuser mask Mean $\pm S D$ & Simple face mask Mean \pm SD & $\mathbf{p}$ & Mean \pm SD \\
\hline Age (year) & $36.3 \pm 13.7$ & $40.7 \pm 15.1$ & $0.1851^{\dagger}$ & $39.1 \pm 14.7$ \\
\hline Weight (kg) & $70.8 \pm 15.6$ & $75.4 \pm 13.2$ & $0.166^{+}$ & $73.8 \pm 14.2$ \\
\hline Height $(\mathrm{cm})$ & $163.5 \pm 7.1$ & $167.8 \pm 9.8$ & $0.026^{+}$ & $166.3 \pm 9.1$ \\
\hline $\mathrm{BMI}\left(\mathrm{kg} / \mathrm{m}^{2}\right)$ & $26.6 \pm 6.2$ & $26.8 \pm 4.1$ & $0.8951^{\dagger}$ & \\
\hline ECG rate (beats/minute) & $92.3 \pm 17.5$ & $87.3 \pm 19.3$ & $0.304^{+}$ & $89.4 \pm 18.7$ \\
\hline $\mathrm{Hgb}(\mathrm{g} / \mathrm{dL})$ & $13.8 \pm 2.3$ & $14.5 \pm 1.7$ & $0.124^{+}$ & $14.3 \pm 1.9$ \\
\hline \multicolumn{5}{|l|}{ Initial ABG levels } \\
\hline $\mathrm{COHb}(\mathrm{mg} / \mathrm{dL})$ & $23.2 \pm 9.1$ & $23.9 \pm 10.5$ & $0.9804^{*}$ & $23.6 \pm 10.0$ \\
\hline $\mathrm{PaO}_{2}(\mathrm{~mm} \mathrm{Hg})$ & $87.7 \pm 7.5$ & $87.8 \pm 8.7$ & $0.8283^{*}$ & $87.8 \pm 8.6$ \\
\hline $\mathrm{SaO}_{2}(\%)$ & $93.6 \pm 14.4$ & $96.3 \pm 3.7$ & $0.4458^{*}$ & $95.3 \pm 9.1$ \\
\hline \multicolumn{5}{|l|}{ After $1 \mathrm{~h}$ of Treat } \\
\hline $\mathrm{COHb}(\mathrm{mg} / \mathrm{dL})$ & $9.6 \pm 5.0$ & $12.8 \pm 6.2$ & $0.0203^{*}$ & $11.7 \pm 5.9$ \\
\hline $\mathrm{PaO}_{2}(\mathrm{~mm} \mathrm{Hg})$ & $224.4 \pm 56.5$ & $183.4 \pm 63.7$ & $0.0046^{*}$ & $198.0 \pm 64.0$ \\
\hline $\mathrm{SaO}_{2}(\%)$ & $97.6 \pm 6.9$ & $98.6 \pm 1.3$ & $0.4327^{*}$ & $98.3 \pm 4.2$ \\
\hline \multicolumn{5}{|c|}{$\begin{array}{l}\text { SD: standard deviation; } \mathrm{BMI} \text { : body mass index; Hgb: hemoglobin; } \mathrm{CO} \text { : carbon monoxide; } \mathrm{PaO}_{2} \text { : partial pressure of } \mathrm{O}_{2^{\prime}}, \mathrm{SaO}_{2} \text { : saturation of } \mathrm{O}_{2^{\prime}} \mathrm{COH}^{\prime} \text { : carboxyhemoglo } \\
\text { bin; ABG: arterial blood gas; Treat: treatment } \\
{ }^{\mathrm{p}} \mathrm{p} \text {-Value was obtained using chi-square test } \\
{ }^{*} \mathrm{p} \text {-Value was obtained using Fisher's exact test } \\
{ }^{p} \mathrm{p} \text { was obtained using Student's t-test } \\
{ }^{*} \text { Results were obtained using Wilcoxon-Mann-Whitney test }\end{array}$} \\
\hline
\end{tabular}


mean value of $\mathrm{COHb}(12.8 \pm 6.2 \mathrm{mg} / \mathrm{dL})$ in patients treated with SMG was lower than that $(9.6 \pm 5.0 \mathrm{mg} / \mathrm{dL})$ in patients treated with DMG ( $Z=-2.32, p=0.0203$ ) (Table 1). The mean values of $\mathrm{SaO}_{2}$ in patients treated with SMG $(98.6 \pm 1.3 \%)$ and DMG $(97.6 \pm 6.9 \%)$ were comparable $(Z=0.79, p=0.4327$ ) (Table 1$)$.

The relationship between the level of $\mathrm{CO}$ and the type of patients' complaints has been evaluated. There was a significant relationship between the level of $\mathrm{CO}$ and the type of complaints $(p=0.001)$. It is also found that nausea, vomiting, and headache were the main complaints in patients who had $\mathrm{COHb} \geq 25 \mathrm{mg} / \mathrm{dL}$, whereas syncope was observed in patients who had $\mathrm{COHb} \geq 34 \mathrm{mg} / \mathrm{dL}$. There was a significant correlation between pre-treatment level of $\mathrm{COHb}$ and respiratory rate $(r=0.293, p=0.008)$.

Admission ECG analyses of the patients were as follows: $80 \%$ normal sinus rhythm (NSR), $17 \%$ tachycardia, and $2.5 \% \mathrm{~T}$ wave inversion. After treatment, tachycardia decreased to $2.5 \%$, and NSR ratio increased to $95 \%$.

Change in $\mathrm{CO}(\triangle \mathrm{CO})$ level was calculated by subtracting the pretreatment value of $\mathrm{CO}$ from the post-treatment value of $\mathrm{CO}$. There was no significant relationship between $\mathrm{BMI}$ and $\triangle \mathrm{CO}$ among patients treated with DMG (correlation analysis $r=-0.12, p=0.522$ and percentage change $r=-0.27, p=0.158$ ). Similarly, among patients treated with SMG, there was no significant relationship between BMI and $\Delta C O$ values $(r=-0.16, p=0.265$ and percentage change $r=-0.14$, $p=0.335$ ). As a result, we found that BMI did not affect the treatment in our study group.

\section{Discussion}

Our study shows that in acute CO intoxication cases, DMG decreases the blood $\mathrm{COHb}$ levels and increases the blood $\mathrm{PaO}_{2}$ levels significantly faster than SMG in the first hour of treatment.

After exposure, $\mathrm{CO}$ enters into the bloodstream rapidly. Compared with $\mathrm{O}_{2}$, CO shows 230-270 times greater affinity to hemoglobin and forms $\mathrm{COHb}$ causing the $\mathrm{O}_{2}$-hemoglobin dissociation curve shift to the left and leading to severe tissue hypoxia $(1,13)$. As tissue hypoxia is the main mechanism of $\mathrm{CO}$ intoxication, to accelerate $\mathrm{CO}$ elimination, normobaric $100 \% \mathrm{O}_{2}$ treatment should be started with a mask as soon as possible for patients whose airway is protected and who have adequate ventilation $(14,15)$. Giving $\mathrm{O}_{2}$ through a mask is easily accessible and a safe treatment and can be made using different types of masks. DMG that provided concentrated $\mathrm{O}_{2}$ directly to the mouth and nose and SMG were two treatment options.

Even with low flow rates, DMG helps to achieve the highest $\mathrm{O}_{2}$ concentration without any risks that may occur in a closed mask system. In DMG, carbon dioxide $\left(\mathrm{CO}_{2}\right)$ retention does not occur, as it is an open system (12). In SMG, $\mathrm{CO}_{2}$ can be inhaled back if $\mathrm{O}_{2}$ flow is insufficient. Patient cannot be fed during the use of SMG.

After vomiting, there is a high risk of aspiration. SMG may not be fit to each face type, and if it is tight fitted, it can cause irritation (16). To avoid inhalation of $\mathrm{CO}_{2}$ and additional respiratory failure load, at least $5 \mathrm{~L} / \mathrm{min}$ flow rate has been proposed (17).
Based on our study results, after the first hour of treatment, DMG can cause a significant decrease in CO levels compared with SMG. It seems to create this effect by increasing the level of $\mathrm{PaO}_{2}$ much faster than SMG. DMG can deliver the same level of $\mathrm{O}_{2}$ more effectively than SMG. In a study by Beecroft et al. (12), they found that using DMG increases the level of $\mathrm{PaO}_{2}$ significantly higher than venture mask even though the $\mathrm{O}_{2}$ flow was low. In other studies, it has been shown that $\mathrm{O}_{2}$ is delivered effectively and reliably with DMG $(18,19)$.

In our study, we did not find any difference between the two groups in terms of $\mathrm{SaO}_{2}$ levels after the first hour of treatment. Although saturation of hemoglobin with $\mathrm{O}_{2}$ increases depending on arterial $\mathrm{PaO}_{2}$ level, this increase is not linear (20).

\section{Study limitations}

Our study has several limitations. First, this is a single-center study. Second, our findings cannot be generalized to intubated patients or patients who need HBOT. Third, this is not a blinded study as the type of mask was seen by both the patient and the doctor.

\section{Conclusion}

In conclusion, in the first hour of CO intoxication treatment, DMG appears to be more effective than SMG. It is because of the fact that $\mathrm{O}_{2}$ can be delivered more effectively by a DMG. It will be beneficial to keep DMG in a quick and easily accessible location. In addition, it may be a more appropriate choice to treat patients with DMG when preparing patients for HBOT.

Ethics Committee Approval: Ethics committee approval was received for this study from the Ethics Committee of Dr. Lutfi Kırdar Kartal Training and Research Hospital (Approval Date: 30.04.2012; No:8951337/1009/141).

Informed Consent: Written informed consent was obtained from all patients who participated in this study.

Peer-review: Externally peer-reviewed.

Author Contributions: Concept - H.H.; Design - H.H., A.C.H.; Supervision H.H., A.C.H.; Resources - H.H., M.T.; Materials - H.H., A.C.H., M.T.; Data Collection and/or Processing - H.H., A.C.H., M.T.; Analysis and/or Interpretation - A.C.H., M.T.; Literature Search - H.H., M.T.; Writing Manuscript - H.H., A.C.H.; Critical Review - H.H., A.C.H.

Acknowledgements: The authors would like to thank Mucahit Emet.

Conflict of Interest: The authors have no conflict of interest to declare.

Financial Disclosure: The authors declared that this study has received no financial support.

\section{References}

1. Lippi G, Rastelli G, Meschi T, Borghi L, Cervellin G. Pathophysiology, clinics, diagnosis and treatment of heart involvement in carbon monoxide poisoning. Clin Biochem. 2012; 45: 1278-85. [CrossRef]

2. Shen $\mathrm{CH}$, Peng CK, Chou YC, Pan KT, Chang SC, Chang SY, et al. Predicting duration of mechanical ventilation in patients with carbon monoxide poisoning. J Crit Care. 2015; 30: 19-24. [CrossRef] 
3. Teerapuncharoen K, Sharma NS, Barker AB, Wille KM, Diaz-Guzman E. Successful treatment of severe carbon monoxide poisoning and refractory shock using extracorporeal membrane oxygenation. Respir Care. 2015; 60: 155-60. [CrossRef]

4. Zahger D, Slutzky O, Almog Y. Severe reversible left ventricular dysfunction inducedvby carbon monoxide intoxication. Am J Emerg Med. 2002; 20: 572-3. [CrossRef]

5. Park EJ, Min YG, Kim GW, Cho JP, Maeng WJ, Choi SC. Pathophysiology of brain injuries in acute carbon monoxide poisoning: A novel hypothesis. Med Hypotheses. 2014; 83: 186-9. [CrossRef]

6. Hocagil H, Tanrıkulu CS, UlkerV, Kaya U, Koca L, Hocagil AC. Asymptomatic myocardial ınjury in a low level of carbon monoxide poisoning. Eurasian J Emerg Med. 2015; 14: 91-3. [CrossRef]

7. Gorman D, Drewry A, Huang-Yin L. The clinical toxicology of carbon monoxide. Toxicology. 2003; 187: 25-38. [CrossRef]

8. Juric-Damijana $M$, Finderle $Z$, Suput $D$, et al. The effectiveness of oxygen therapy in carbon monoxide poisoning is pressure- and time-dependent: A study on cultured astrocytesoriginal. Toxicology. 2015; 233: 16-23.

9. Hampson-Neil B, Piantadosi-Claude A, Thom-Stephen R. Practice recommendations in the diagnosis, management, and prevention of carbon monoxide poisoning. Am J Respir Crit Care Med. 2012; 186: 1095101. [CrossRef]

10. Suena-Winnie W, Ridleya B, Blakneya G, Higgins TN. Comparison of lactate, bilirubin and hemoglobin $\mathrm{F}$ concentrations obtained by the $\mathrm{ABL}$ 700 series blood gas analyzers with laboratory methods. Clin Biochem. 2003; 36: 103-7. [CrossRef]
11. Pyne-David B, Boston T, David-Martin T, Logan A. Evaluation of the Lactate Pro blood lactate analyser. Eur J Appl Physiol. 2000; 82: 112-6. [CrossRef]

12. Beecroft JM, Hanly PJ. Hanly-Patrick J Comparison of the OxyMask and Venturi mask in the delivery of supplemental oxygen: Pilot study in oxygen-dependent patients. Can Respir J 2006; 13: 247-52. [CrossRef]

13. Bateman-Nicholas D. Carbon monoxide. Medicine. 2012; 40: 115-6. [CrossRef]

14. Prockop-Leon D, Chichkova-Rossitza I. Carbon monoxide intoxication: An updated review. J Neurol Sci. 2007; 262: 122-30. [CrossRef]

15. Buckley NA1, Juurlink DN, Isbister G, Bennett MH, Lavonas EJ. Hyperbaric oxygen for carbon monoxide poisoning. Cochrane Database Syst Rev. 2011; 4: CD002041.

16. Kallstrom TJ. American Association for Respiratory Care. AARC Clinical Practice Guideline: Oxygen therapy in the acute care facility. 2002 revision and update. Respir Care. 2002; 47: 707-16.

17. Jensen AG, Johnson A, Sandstedt S. Rebreathing during oxygen treatment with face mask: the effect of oxygen flow rates on ventilation. Acta Anaesthesiol Scand. 1991; 35: 289-92. [CrossRef]

18. Lamb K, Piper D. Southmedic OxyMask (TM) compared with the Hudson $\mathrm{RCl}\left({ }^{\oplus}\right)$ Non-Rebreather Mask (TM): Safety and performance comparison. Can J Respir Ther. 2016; 52: 13-5.

19. Paul JE, Hangan $\mathrm{H}$, Hajgato J. The OxyMask ${ }^{\mathrm{TM}}$ development and performance in healthy volunteers. Med Devices. 2009; 2: 9-17.

20. Poets CF, Southall DP. Noninvasive monitoring of oxygenation in infants and children: practical consideration and areas of concern. Pediatrics.1994; 93: 737-46. 